\title{
DE PIVETE A FUNQUEIRO: GENEALOGIA DE UMA ALTERIDADE
}

\author{
ANGELA ARRUDA \\ Professora do Instituto de Psicologia e Pós-Graduação em Psicologia da \\ Universidade Federal do Rio de Janeiro \\ arrudaa@centroin.com.br
}

\section{MARILENA JAMUR}

Professora aposentada da Escola de Serviço Social da Pontifícia Universidade Católica do Rio de Janeiro marilena.jamur@oi.com.br

\section{THIAGO MELICIO}

Mestre em Psicologia pelo Instituto de Psicologia da

Universidade Federal do Rio Janeiro

tmelicio@yahoo.com.br

\section{FELIPE BARROSO}

Graduando do Instituto de Psicologia da Universidade Federal do Rio de Janeiro barroso.fellipe@gmail.com

\section{RESUMO}

Com base na teoria das representações sociais de Moscovici e a partir de contextualizações do fenômeno dos arrastões, esse texto se propõe a discutir elementos que respondam às questões: por que discursos criminalizantes, que afirmam a periculosidade do funkeiro, se fizeram tão presentes desde o início da década de noventa no Rio de Janeiro? Como esses discursos, que apontam para uma determinada construção social do funkeiro, interferiram na relação do funk com a sociedade? A discussão passa pela compreensão dos dispositivos criados na sociedade carioca daquele período para a solução de problemas com os quais ela se via confrontada. Tratase de tentar compreender como, em certo momento, o funkeiro ganha um perfil amplamente difundido como problema que requer um tipo de intervenção específica. REPRESENTAÇÕES SOCIAIS - FUNK - VIOLÊNCIA - RIO DE JANEIRO

\section{ABSTRACT}

FROM PETTY THIEF TO FUNK FAN: THE GENEALOGY OF ALTERITY. Based on the theory of the social representations of Moscovici and from the contextualization of the phenomenon of street gang mass robberies, this text proposes to discuss elements that respond to the following questions. Why have criminalizing discourses, which claim how dangerous funk fans are, been so 
evident since the start of the 1990s in Rio de Janeiro? How do these discourses, which indicate a certain social construction of the funk fan, interfere in the relationship of funk with society? The discussion starts with an understanding of the devices created in the Rio de Janeiro society of that period for solving the problems with which it saw itself confronted. This is an attempt to understand how, at a particular point in time, the funk fan received a widely disclosed profile as a problem that requires a specific type of intervention.

SOCIAL REPRESENTATIONS - FUNK - VIOLENCE - RIO DE JANEIRO

O mundo funk agasalha em seu espaço paus, pedras e armas de fogo. Grupos de jovens, em busca de divertimento, espalham muito mais terror do que alegria. [...] Não há distinção entre funk, favela e tráfico de drogas no Rio. A maioria dos funkeiros não é vinculada ao tráfico, mas se divide filosoficamente entre Comando Vermelho e Terceiro Comando e vê como heróis os líderes do crime organizado [...] A presença do tráfico de drogas nos bastidores reafirma a convicção de que os bailes funk são um caso de polícia. (Jornal do Brasil, apud Herschmann, 2005)

Este inflamado editorial é típico do despontar do funk como fenômeno amplamente conhecido e comentado, não só pela sociedade brasileira, mas também cada vez mais mundo afora. Basta voltar, por alguns minutos, a atenção para a mídia televisiva para verificar que ele está em novelas, programas variados e peças publicitárias. A "descida do morro" e a "conquista do asfalto" se percebe na batida grave que sai dos aparelhos de som de carros importados ou nas festas de universitários e aniversários de crianças de classe média e alta.

Apesar deste trânsito aparentemente livre, o funk trafega por uma complexa relação de forças, na qual se destaca a construção da figura do funqueiro operada pela sociedade. Desse modo, pode-se chegar a formular as seguintes questões, que tentaremos debater adiante: por que discursos, como o do editorial acima, se fizeram tão presentes desde o início da década de noventa? Como esses discursos, que apontam para uma determinada construção do funqueiro, um certo entendimento a seu respeito, interferiram na relação do funk com a sociedade?

Esta discussão passa pela compreensão dos dispositivos criados na sociedade carioca daquele período para a solução de problemas com os quais ela se via confrontada. Trata-se de tentar compreender como, a partir de certo momento, o funqueiro ganha um perfil amplamente difundido como problema que requer intervenção específica.

Na busca de pistas para a compreensão da construção desse novo personagem, do conhecimento histórico a respeito, nos apoiamos na teoria das 
representações sociais de Moscovici e Jodelet, e procuramos aceder a essa realidade complexa de modo indireto, indiciário, sobre conjecturas (Ginzburg, 1989), inferindo possíveis causas a partir dos seus efeitos.

Textos de jornais e revistas, programas audiovisuais, entre a virada e decorrer dos anos 1990, assim como reflexões de alguns autores que se debruçaram sobre o universo do funk, comparecem aqui para ilustrar o olhar psicossocial sobre as condições em que a imagem do funkeiro ganha um contorno marcado pela sua associação à criminalidade.

\section{O ARRASTÃO DE I8 DE OUTUBRO DE 1992: A EMERGÊNCIA DE UM PERSONAGEM}

O arrastão de 18 de outubro de 1992 constitui um marco na história do funk carioca. Ele dispara uma construção criminalizante da figura do funqueiro pela mídia. Na verdade, o episódio convoca tensões e conflitos provocados pelo encontro de classes sociais distintas, tão bem retratado por documentário exibido pela Rede Manchete (Pobres vão à praia, 1989). Nele, mostrava-se a via crucis de suburbanos para chegar à praia no fim de semana antes da inauguração do Túnel Rebouças, e a recepção nada entusiasta dos moradores da Zona Sul diante dessas visitas.

É claro que o funk não surgiu no cenário midiático com os arrastões, mas eles concorreram para projetá-lo nacionalmente, colocando os jovens funkeiros especialmente nas seções policiais e depois também nos cadernos culturais. Vianna afirma também que ao concluir seu trabalho de pesquisa, no final dos anos 80, o funk não era representado na grande imprensa como uma manifestação ameaçadora da ordem pública, mas sim como uma forma de lazer dos jovens dos subúrbios, como retrata a Revista Veja (apud Vianna, 1996, p. 4): "Para uma parcela considerável da juventude carioca, funk é bem mais que isso - é uma palavra mágica sob a qual se abriga um ritual. Esses jovens formam uma comunidade com códigos de conduta próprios na maneira de se vestir, falar, se divertir e namorar...".

Da mesma maneira, com base em levantamento realizado sobre o funk na mídia impressa, Herschmann (2005) constata que entre 1990 e 199| esse gênero musical apareceu três vezes na mídia na seção dos cadernos culturais. Esse quadro muda a partir de 1992, quando há um aumento de referências 
ao funk, com predomínio nas seções policiais. Em 1995, dos 40 artigos por ele encontrados, 65\% estavam nas seções policiais e Cidade, e 35\% nos cadernos de cultura.

Para Vianna (1996), depois dos arrastões, os bailes funk passaram a ser vistos, antes de tudo, como um espaço de violência e não mais de divertimento. Para Herschmann (2005), o funk vai então adquirir uma nova dimensão, a partir de sua intensa veiculação na mídia, colocando em discussão o lugar do jovem pobre no debate político e intelectual do país. Os arrastões possibilitaram à mídia fazer dos funqueiros bodes expiatórios, como uma forma de externalizar o mal e garantir a continuidade de uma determinada estrutura/ordem social. Segundo Jodelet (1 999), a exclusão comporta sempre uma organização específica de relações interpessoais ou intergrupais por meio das quais ela se traduz, e se mantém graças a uma construção da alteridade baseada nas representações sociais que a comunicação social e midiática contribuem para difundir.

O funqueiro, porém, não ficou estigmatizado do dia para a noite, depois do arrastão de 1992. O acontecimento possibilitou a criação de um personagem que já estava sendo delineado no final dos anos 80. Autores como Zaluar ( 1994), Malaguti (apud Medeiros, 2006, Valladares (2000) apontam um medo antigo das elites cariocas em relação às favelas - e aos seus moradores, hoje incluindo funqueiros. Como diz Mary Douglas (|99|), o que não se enquadra no nosso sistema de classificação e, portanto, de ordenação do mundo, segundo nossa cultura - ou o que está na margem desse sistema - é com frequência visto como ameaçador e, por conseguinte, como impuro, sujo, produtor de repulsa e de medo. Esse medo teria crescido a partir dos anos 1990, também por conta de um novo cenário político que se delineava.

Em 1989, após 29 anos sem eleições diretas para presidente da República, Fernando Collor de Mello triunfa, com a imagem de político jovem, autônomo, comprometido com o povo, construída por uma forte estratégia de marketing. Concorreram para a sua vitória, por um lado, o temor dos grupos conservadores de ver um líder de esquerda, o ex-operário Luís Ignácio Lula da Silva, no poder. Por outro, a instabilidade política (greves) e econômica que assustava a classe média brasileira: 1989 terminou com uma inflação de mais de 1.700\% (Meneghello, 1994). Um dia após assumir a Presidência, em março de 1990, Collor anunciava um plano econômico que comportava, dentre outras medidas, o confisco temporário dos depósitos bancários e aplicações 
financeiras, o congelamento de salários, a demissão de funcionários públicos e a privatização das estatais. $\bigcirc$ fracasso desse plano e as denúncias sobre um esquema de corrupção do governo federal abalaram o prestígio de Collor. No final de 1992, após um longo processo instaurado no legislativo, ele renuncia à Presidência antes de ser sentenciado com o impeachment, e perder seus direitos políticos por oito anos. Diante desse quadro conturbado, o pessimismo tomava conta da população brasileira. Segundo pesquisa do Instituto Gallup, publicada no Jornal do Brasil, 41\% dos brasileiros consideravam I99| como o pior dos últimos dez anos e 54\% acreditavam que o ano seguinte seria ainda pior ("Brasileiro elege | 991...", | 991).

Nesta mesma época, outro tipo de cenário, ligado a organizações criminosas e à violência urbana também se apresentava sob uma nova configuração. A dinâmica do tráfico de drogas no Rio de Janeiro passava por uma profunda transformação com a chegada de cocaína em grande quantidade no fim dos anos 70 e, mais marcadamente, no começo dos 80 . A cidade se torna um mercado de varejo e um ponto estratégico para o trânsito da droga que entra pelos portos, aeroportos e rodovias para outros países (Dowdney, 2003). As favelas, com sua geografia de becos estreitos, morros altos, de difícil acesso, caminhos sinuosos e becos sem saída, acabam sendo locais perfeitos para a instalação de pontos de venda de drogas.

Maiolino (2005) reforça a afirmação de que uma nova situação se desenvolve nesta década nas favelas, com a presença mais representativa dos banqueiros do jogo de bicho e de grupos ligados ao tráfico de drogas. Esses grupos passam a exercer controle sobre as organizações locais e seus moradores, ampliando gradativamente sua atuação interna nas favelas. A década termina com o aumento da complexidade dos problemas que envolvem esses locais, como o próprio tráfico. A entrada da cocaína aumenta enormemente os lucros e assim intensifica-se o poder de fogo dos traficantes, com a aquisição de armamentos cada vez mais pesados, para a defesa do território contra as invasões da polícia, que também aumentam, e de outros grupos rivais que disputam os pontos de venda da droga. Não é novo o discurso que associa os pobres a uma "classe perigosa", porém cresce mais ainda a mobilização para os problemas urbanos decorrentes da existência desses espaços na cidade.

O cenário político-econômico nacional turbulento, por sua vez, repercutia no Rio de Janeiro, onde a população residente em favelas cresceu 40,48\% 
entre 1980 e 199I, contra II, I5\% na década anterior, conforme Censo de 2000, do Instituto Brasileiro de Geografia e Estatística - IBGE (apud Fernandes, 2005). A circulação dessa massa de 'favelados' que se tornava cada vez mais expressiva e visível, gerava conflitos na cidade.

O termo "arrastão", antes mesmo de ser associado ao universo funk, surgia na mídia entre 1989 e 1990, para designar ações de "pivetes" que praticavam assaltos em bandos, principalmente nas praias da Zona Sul da cidade (Herschmann, 2005). O sentimento por parte dos setores dominantes da sociedade carioca de que suas praias haviam sido invadidas pelos favelados, retirava-Ihes "o prazer de suas caminhadas pelas ruas limpas e urbanizadas da Zona Sul, agora repletas de "pivetes" e maltrapilhos, de cujo local de origem jamais deveriam ter saído" (Fernandes, 2005, p. 8).

Há, portanto, nesse período, um discurso catalisado pela mídia, de incômodo em relação à convivência forçada com os setores populares da cidade (Fernandes, 2005). É o que demonstra um trecho de reportagem do Jornal do Brasil, de 3/I I/1991:

As padarias escondem a mortadela, retiram os croissants dos balcões e trancam o freezer a cadeado. [...] Ipanema e Leblon, que já produziram praias inesquecíveis de moda, política, comportamento e cultura, agora se preparam para conviver com o arrastão, uma assustadora onda de assaltantes, sinistro emblema do que se anuncia como o mais sujo, caótico e violento verão da história da cidade. [...] Nos sábados e domingos de sol, os moradores cedem a praia para mais de 100 mil suburbanos de todos os cantos da cidade. A Zona Sul, assustada, os recebe mal, sem o menor interesse em distinguir, dentro dos ônibus lotados, a fronteira entre a breguice, a pobreza e a delinquência. (Rodrigues, |99|)

Duas trágicas chacinas marcaram o Rio de Janeiro em 1993 - a da Candelária e a de Vigário Geral. Em julho, seis policiais militares - PMs - assassinaram sete menores que dormiam debaixo de marquises, no centro do Rio de Janeiro; 16 dias depois, 21 pessoas foram assassinadas na favela de Vigário Geral por 50 PMs encapuzados, em represália à morte de quatro policiais por traficantes de

I. O termo favelado pode ser lido também como suburbano, pivete, menino de rua, mendigo etc. Ou seja, referido a todos aqueles pertencentes às classes populares. 
drogas da região. $\bigcirc$ que a princípio parecia apenas um desconforto dos setores dominantes, com as chacinas termina revelando a que ponto a produção de uma alteridade radical podia entrar em ação, transformando-se em ações de violência contra os pobres.

Funqueiro, antes apenas designativo de alguém que frequenta bailes funk para se divertir, dançar, "azarar", se torna um termo estigmatizante justamente durante esse conturbado período, pela associação de sua imagem às favelas e periferias, espaços dos quais a elite carioca queria se afastar e distinguir; o termo passa a ser sinônimo de "pivete", "favelado" e outras denominações ligadas à "marginalidade".

\section{FUNQUEIRO: NOVO ATOR, VELHOS CONFLITOS}

Não é difícil imaginar por que o arrastão de 1992 foi facilmente identificado como um ato de violência praticado por funqueiros, justificando várias medidas políticas de coerção ao universo funk e aos seus adeptos, mesmo quando os números apontavam para uma outra realidade.

Nilo Batista, vice-governador do Rio e secretário de Justiça e de Polícia Civil à época, faz uma correção, 14 anos depois do acontecimento, afirmando que não houve nenhuma vítima nem pessoa ferida no incidente, no máximo o furto de uma toalha ou um par de sandálias havaianas (Medeiros, 2006). Infelizmente, esse reconhecimento veio tarde demais, e a associação entre violência e funqueiro já estava incorporada, determinando a forma como essa expressão cultural seria encarada e tratada pelo poder público nos anos posteriores. No verão de 1992, ganha evidência a produção da alteridade em torno do funqueiro. Após o fenômeno emergente do arrastão nas praias cariocas, surge a necessidade, por parte da mídia e dos poderes públicos, de produzir uma explicação que desse sentido a essa situação, que possibilitasse sua compreensão e consequente atuação sobre o problema. Segundo Joffe (2003, p.3 17), "quando ocorrem mudanças ameaçadoras no ambiente social, as representações da mudança servem para dar às pessoas um sentimento de controle da situação potencialmente incontrolável".

A alteridade surge como um processo que serve de "fermento" para a renovação dos repertórios mentais (Arruda, 2002). Assim, para estabelecer um novo senso comum, novos sistemas representacionais são convocados pelas 
informações produzidas. No intuito de tornar um "novo fenômeno" algo familiar, passível de ser entendido e teorizado, os meios de informação utilizam-se de imagens e ideias anteriores a ele. $\bigcirc$ funk, na medida em que foi reinventado pelos cariocas, tornou-se um estilo musical facilmente identificado como pertencente às camadas populares, tanto em relação à sua produção, quanto a seu consumo. O funqueiro, como "bode expiatório", passa a ser ancorado em imagens dos grupos marginais que simbolizam a ameaça à sociedade².

Para a teoria das representações sociais, o conhecimento que as pessoas têm sobre grupos que podem ser alvo de projeção é construído tanto por memórias coletivas, como pelas teorias que circulam na comunidade científica, nos meios de comunicação de massa e nas conversações do dia a dia. Criminalizar o funqueiro naquele momento carregava uma sintonia com representações antigas, construídas desde meados do século XIX, sobre qualquer figura suspeita que circulava na cidade, fantasma que se tornava cada vez mais ameaçador à medida que as leis contra a escravidão iam se multiplicando e os antigos escravos ganhavam as ruas (Bicalho, 2005). De forma geral tratava-se do negro e pobre, que era associado natural e indissoluvelmente a pobreza e criminalidade (Coimbra, 2003).

Essas antigas representações hegemônicas sobre aqueles grupos sociais no Rio de Janeiro vieram bem a calhar num momento em que o chamado "arrastão" despontou como um grande perturbador da "ordem natural das coisas" para a classe média carioca. Patrícia de Farias (2003) cita uma pesquisa com as "galeras" de Vigário Geral, que mostra os conflitos na praia como briga de grupos rivais e disputa de territórios. A galera do "Galo" (Morro do Cantagalo) passou a não sustentar a presença da galera do Borel, alegando a forte vigilância policial. Tratava-se de um rearranjo das galeras no território das praias, e o arrastão teria contribuído para a rearrumação de forças em torno dos pontos da orla. Na visão dos banhistas, contudo, foi uma insuportável

2. Para a Psicologia Social clássica, o "bode expiatório" dá vazão a tendências culturalmente reprovadas, aos conflitos que elas geram, por meio de mecanismos de projeção, expressando atitudes de antipatia a diversos grupos, em particular grupos minoritários (Krech, Crutchfield, Ballachey, 1975). Possui origens históricas que atravessam vários ritos religiosos (Enriquez, 1983; Pereira, 1990); as características de tais práticas se transformam no tempo, entretanto, as dinâmicas psicossociais que as mobilizam persistem, fazendo com que em determinados contextos sociológicos e políticos, sobretudo em situações novas e adversas, elas se reatualizem em termos de repertórios e de alvos. 
perturbação que deixou uma marca indelével no imaginário da praia no Rio de Janeiro (Farias, 2003). Essa perturbação necessitava ser elaborada, e isto se fez com os repertórios disponíveis.

Não era o funqueiro que estava sendo criminalizado, mas o jovem pobre, negro e favelado. O funqueiro era sua objetivação no momento ${ }^{3}$. Esses jovens, multidão em movimento agressivo para os padrões locais, surgem como algo inquietante. $\bigcirc$ fenômeno do confronto de galeras na praia, território sagrado da classe média da Zona Sul do Rio de Janeiro, é algo inusitado, de modo geral - e inaceitável para a população que frequenta esse espaço. Na verdade, então, o que se está traduzindo é esta invasão de território por "bárbaros", estranhos no ninho, que vêm perturbar a paz ensolarada do paraíso urbano. No caso, as imagens já estavam lá, e se reacomodariam, ganhando nova denominação. A denominação dada foi o arrastão, cujo personagem principal logo seria identificado ao funqueiro ${ }^{4}$.

\section{DEMARCANDO TERRITÓRIOS}

Se as favelas e seus habitantes tinham uma longa trajetória de discriminação, também a territorialidade das classes médias e altas, a divisão da cidade em zonas mais e menos privilegiadas tinha seu enraizamento no imaginário da cidade. O documentário Os pobres vão à praia registra o enorme desconforto dos moradores da Zona Sul com a presença dos "suburbanos" e "farofeiros" no seu território.

3. Para a Teoria das Representações Sociais, a objetivação é um dos processos de construção das representações sociais, transformando noções abstratas em imagens, tornando intercambiáveis conceito e percepto. "Objetivar é reabsorver um excesso de significações materializando-as" (Moscovici, 1984). No caso, o conjunto variado de significações historicamente construídas do jovem pobre, negro e favelado é materializado na imagem do funqueiro.

4. $\bigcirc$ episódio também teria sido aproveitado pelo candidato a prefeito do Rio, César Maia (Partido do Movimento Democrática Brasileiro - PMDB), naquele momento, e visibilizado para reforçar sua campanha contra Benedita da Silva, candidata "autointitulada mulher, negra, favelada, representante das comunidades mais pobres da cidade, membro do Partido dos Trabalhadores - PT" (Farias, 2003, p. 179), se ela vencesse, a tendência seria a confusão se alastrar pela cidade, uma vez que os protagonistas dos arrastões eram grupos que ela afirmava querer representar na prefeitura. 
As favelas, que já compunham a paisagem da cidade do Rio de Janeiro desde fins do século XIX, ganham importância no cenário urbano no início do século XX, quando o Rio ainda era capital do Brasil, ao serem implementadas políticas públicas com o objetivo de transformá-la em uma capital nos moldes europeus. A demolição de cortiços do centro da cidade, por exemplo, provocou o êxodo de moradores para as encostas dos morros próximos, como forma de continuar morando perto dos seus locais de trabalho. A geografia do Rio de Janeiro possibilitou que o pessoal "do morro" não fosse jamais esquecido pelos cidadãos "do asfalto", porque o encontro de mar e montanha une os moradores que ocupam a faixa de terra mais valorizada da cidade - a litorânea - e os habitantes das encostas. São territórios conflitantes que se encontram, mas não devem se misturar, segundo a perspectiva dos habitantes da zona praieira.

Haesbaert (2002), afirma que o território expressa uma relação desigual de forças, envolvendo o domínio ou controle político-econômico do espaço e sua apropriação simbólica, numa tentativa por parte de um indivíduo ou de grupos de influenciar ou controlar pessoas, fenômenos e relações mediante a delimitação e a afirmação do controle sobre uma área geográfica. O espaço é anterior ao território. Este somente se forma a partir do espaço e se caracteriza por seu valor de uso em um campo de possíveis, resultado de uma ação conduzida por um ator/atores, em diferenciados níveis. A apropriação de um espaço o torna territorializado em meio a um campo de poder que está em disputa (Raffestin, 1993). A classe média, expressa o desejo de demarcar status e identidade pelo domínio e pela exclusividade sobre uma parte do espaço urbano ${ }^{5}$. Assim, a territorialização de determinadas áreas envolve processos de apropriação e controle inscritos em um campo de poder (físico e simbólico), mas também de laços de identidade que tentam homogeneizar esse território, seja por uma identidade territorial recoberta de afetos e/ou uma fronteira definidora de alteridade. Contudo, essa territorialidade é dinâmica, como sugerem Raffestin (1993) e Haesbaert (2004). Ela resume, de algum modo, a maneira pela qual as sociedades se expressam, em determinado momento, o que faz

5. O território hoje também expressa o poder de dominação e de lucro das facções criminosas, pelo uso dos espaços em suas atividades, o que parece um contraponto ao que a classe média operou como demarcação de território na cidade. 
com que a sua análise só seja possível pela apreensão das forças em confronto, postas no seu contexto sócio-histórico e espaço-temporal.

Esse processo ficou evidente com a chegada da corte ao Brasil e a ocupação forçada de casas para receberem os nobres portugueses, que expulsou moradores do centro da cidade, provocando um reajuste na elite local: perda de local de moradia, do lugar mais alto no topo da pirâmide social, que foi compensada com títulos de nobreza e outras benesses. $\bigcirc$ processo prosseguiu com o controle das ruas após a libertação dos escravos, levando à criação do que veio a ser a Polícia Militar, destinada a garantir a segurança e tranquilidade dos antigos senhores (Bicalho, 2005). A reforma Pereira Passos, o "bota-abaixo", é outra expressão da demarcação de território dentro da cidade, que expulsou os pobres do centro para criar um espaço condizente com a "moderna" capital da república. Os mais abastados já estavam se transferindo para outros bairros, como o Cosme Velho, o Engenho da Rainha, onde podiam retirar-se para suas quintas sem ser incomodados (Abreu, 1994). Os dois últimos séculos, no Rio de Janeiro, portanto, foram marcados por processos de realocação dos espaços com base em interesses e projetos políticos e econômicos das elites, e de seus nexos simbólicos.

As políticas de demolições e remoções da população das favelas, implantadas por diversos governos, fracassaram na tentativa de abolir completamente os incômodos vizinhos que poluíam os "cartões-postais" da cidade. A favela ficou marcada no imaginário popular como o lugar da carência, o favelado sendo frequentemente tomado como bode expiatório dos problemas da cidade, aquele "outro" de quem o morador civilizado quer se distinguir. Segundo Alvito e Zaluar

.... despeito de diferentes roupagens, sempre de acordo com um contexto histórico específico, o favelado foi um fantasma, um outro construído de acordo com o tipo de identidade de cidadão urbano que estava sendo elaborada, presidida pelo higienismo, pelo desenvolvimentismo ou, mais recentemente, pelas relações autorreguláveis do mercado e pela globalização. (2003, p. 15)

Contemporaneamente vivemos processos de multiterritorialidade, territorialidade em redes e outras (Haesbaert, 2004). A capilaridade da cidade, que 
não é mais dividida por trincheiras de classe, o trânsito de grupos diferentes por espaços diferentes mostra esse dinamismo, que entretanto não é vivido com a mesma tranquilidade por todos, uma vez que os espaços são também lugares de afetos, de memórias e fantasias.

O arrastão de 1992, portanto, cristaliza tensões entre classes e grupos sociais, propulsadas, dentre outros motivos, pelo aumento da locomoção e acesso dos moradores da Zona Norte a outras áreas desde o final dos anos 80 , facilitando a chegada às praias da Zona Sul - entendidas por muitos habitantes dessa área como parte do seu território, por isso, o sentimento de que seu espaço estava sendo invadido. A "mistura" que a chegada de gente "de fora" ocasiona se associa a "sujeira", "paraibada" (Farias, 2003, p. 177). Assim, era preciso colocar ordem nessa "desordem", naquilo que não estava no seu lugar e simbolizava, ao mesmo tempo, perigo e poder (Douglas, |99|). Estratégias de evitação incluíram o "gelo", ou seja, ignorar o outro, não conversar, se afastar, ou a debandada: passar a frequentar outra praia, mais longe (Farias, 2003).

\section{A PRODUÇÃO DE ALTERIDADE(S)}

O encontro com o outro pode gerar problemas, mesmo independente das diferenças raciais, culturais e econômicas, na medida em que não se trata apenas do reconhecimento da existência do outro, mas do reconhecimento de um sujeito legítimo, que não só me constitui enquanto eu, mas também se apresenta como portador de um projeto que lhe é próprio (Jovchelovitch, 1998). O desconforto desse encontro advém justamente do fato de o outro não ser tão diferente quanto se gostaria que fosse, mas um semelhante que não conseguimos situar bem (Arruda, 1998). Assim, o insuportável é que o outro não é "somente" o outro, porque:

....ainda é necessário que ele me implique nele, me ingira, me absorva na sua alteridade; que me vire e revire no seu próprio interior, para me jogar na cara uma imagem minha desconhecida por mim e com a qual me reveste. $\bigcirc$ outro me inflige uma dupla violência: violência da alteridade como tal, e violência da alteridade porque tenta me identificar, porque corrói e soterra a minha identidade. (Dadoun, 1998, p. 66) 
Contudo, é sustentado na diferença que o "eu" pode existir e, principalmente, construir a sua identidade. As múltiplas formas de envolvimento com o outro não só acarretam diferentes concepções do próprio eu, como também diferentes relações entre o eu e o outro (Jovchelovitch, 1998.). A cisão radical entre o eu e o outro permite um maior controle identitário, pois o outro, que é excluído, deixa claro quais comportamentos os membros da sociedade devem evitar, desempenhando um papel importante na coesão e identidade do grupo dominante. Dessa forma, o sujeito só pode construir a sua identidade pelo reconhecimento e relacionamento com aquilo que ele não é. É principalmente esse encontro com o diferente que permite ao sujeito delimitar quem ele é. Assim,

.... inferno que o outro nos oferece é o inferno de uma vida onde a onipotência do desejo do sujeito é um sonho vão, sempre limitado pelo desejo do outro, pelo seu olhar, seu gesto e reconhecimento. Mas esse inferno não se compara ao inferno que a experiência de nossa época ofereceu, e que nossa memória histórica deve preservar: é somente no pesadelo de uma vida social de desejos irrestritos que o mais obscuro dos totalitarismos pode existir. (Jovchelovitch, 1998, p. 82)

Joffe (2003, p. 314), comenta que "o caráter estranho dos rituais pertencentes a grupos externos é usado tanto para denunciar o grupo externo, como para distanciar o próprio grupo desse tipo de ritual". Portanto, na negociação da diferença em relação ao funqueiro, operada pelos meios de comunicação, características que associam suas práticas à "barbárie" ganham maior evidência no intuito de acentuar a sua distância em relação ao grupo hegemônico. Vianna, ao comentar sobre os jornalistas que procuraram retratar os bailes funk, diz:

A maioria tinha ido a um ou dois bailes na vida. Preferiam ir aos chamados "bailes de corredor", os mais violentos, e generalizavam o que viam ali para todo o circuito de centenas de bailes. Muitas vezes fotógrafos pediram para os dançarinos simularem brigas para suas imagens terem mais "impacto" (2006, p. 3).

Em outro editorial, de 19/7/1995, o Jornal do Brasil decretava: "Os bailes funk são um caso de polícia e deveriam ser combatidos em nome da paz social" (apud Vianna, 2006) 
É importante notar que, conforme a teoria das representações sociais, a alteridade construída de um objeto aparece como uma qualificação que lhe é atribuída (Jodelet, 2002). Assim, a alteridade se elabora no seio de uma relação social e em torno de uma diferença, que se dá em determinado(s) contexto(s). Essa diferença será negociada de acordo com a posição de cada grupo, assim como das formas de relações que estabelecem no tecido social. Desse modo, há uma disputa entre as representações e nessa disputa, de acordo com o jogo de interesses, uma determinada representação ganha evidência, produzindo esquemas estereotipados, resultado de processos de seleção e simplificação próprios ao pensamento do senso comum (Jodelet, 1999). Nesse sentido, é esperado que as representações veiculadas na mídia adquiram maior visibilidade e passem a ser objeto de reapropriação pelos/dos sujeitos.

$\bigcirc$ arrastão produziu, portanto, uma situação inusitada que, para ser compreendida, buscou um terreno conhecido ao qual se incorporar: a figura do funqueiro foi invocada e ancorada aos sistemas representacionais ligados à marginalidade, e colocado pela mídia como protagonista da invasão do território 'exclusivo' dos moradores da Zona Sul. O funqueiro passou a ser associado ao frequentador dos bailes funk marcados pela violência, ator da promiscuidade e da criminalidade ligada ao tráfico de drogas. Sua figura tornou-se a síntese e o emblema desse universo e dos arrastões, uma figura destoante do espaço que invadia. Reforça-se assim um conflito no qual a oposição entre o polo dos "locais" e o dos "não-locais", a rivalidade entre lugares de moradia, na verdade, traz embutida a diferença entre cores de pele, classes e grupos sociais. Como disseram entrevistados na época, "quem traz o terror é o pessoal de fora" (Farias, 2003, p. 183).

Contudo, outras representações foram construídas sobre o funqueiro. Certamente, as dos próprios jovens frequentadores dos bailes funk, por exemplo. Vianna (1988), em pesquisa pioneira, traz uma análise iluminadora sobre eles. Mais tarde (Vianna, 1996) pondera que as brigas retratadas nos bailes, no geral, eram consequência de rivalidades entre favelas, anteriores à chegada do funk ao Rio de Janeiro, na década de 70. Devido à exclusão dos bailes "das áreas nobres", os chefes do tráfico, cada vez mais jovens, que dominam os morros, passaram a proteger ou mesmo promover os bailes. "Essa parte da história do funk, e da 'criminalização' do funk, ainda está para ser escrita. [...] Os jornais não publicam exatamente fatos, mas sim interpretações sobre os fatos" (Vianna, 2006, p. 3). Da mesma forma, o tratamento dado pela mídia a 
grupos 'de choque', jovens de classe média, treinados ou não em lutas marciais como o jiu-jitsu, que usavam a violência não só para contrapor as galeras, mas também para sublinhar outras alteridades, com ataques a homossexuais, índios, nordestinos, foi bem diverso do que receberam os jovens identificados como funqueiros.

Toda representação, alerta Jodelet ( 1984 ), é representação de algo por alguém. Desta forma, tanto a representação comentada por Vianna como a difundida pela mídia é operada segundo o processo que dá sentido ao que nos cerca, tornando o estranho em algo familiar.

O próprio funk, por sua vez, opera uma desterritorialização e uma reterritorialização (Canclini, 1998), ao conseguir penetrar os espaços da classe média com seu formato contra-hegemônico - o testemunho da vida e da violência das favelas, a erotização precoce e a carência educacional expressa no uso da língua (Laignier, 2008). Ironicamente, recolocando a periferia no centro da difusão cultural massiva, os funqueiros são indesejáveis, mas sua produção musical se infiltra mais e mais no território das elites, mostrando a porosidade das fronteiras urbanas.

De acordo com o exposto, os primeiros indícios das condições para que a alteridade do funqueiro se produza sobre o pano de fundo da criminalização, são: as relações que a sociedade historicamente estabeleceu com os moradores da favela, na sua maioria pobres e negros, enquadrando-os na categoria de marginais; as relações estabelecidas com o espaço urbano pelos grupos dominantes, gerando uma territorialização da cidade - ela também histórica; uma conjuntura de dificuldades econômicas e políticas acompanhada por melhores condições de acesso dos "estrangeiros" ao território "exclusivo" das classes médias e altas; a visibilidade que a manifestação cultural do funk ganhou e a forma como ela se deu na mídia. Acrescente-se ainda as práticas de exclusão e discriminação apoiadas em referenciais próximos daqueles contidos nos processos de higienização da capital fluminense, presentes, portanto, no repertório psicossocial fluminense e carioca, levando, como observa Farias (2003), a objetivar o funqueiro como marginal que porta "paus, pedras e armas de fogo".

Uma alteridade radical projeta sobre o funqueiro muito daquilo que a sociedade deseja eliminar de seu interior, justificando, assim, intensas medidas de repressão. É ainda Farias quem complementa, dando destaque ao que consideramos, na perspectiva psicossocial das representações sociais, como a operação de dar sentido a um objeto não familiar e incorporar uma nova clas- 
sificação ao repertório simbólico grupal - modificando tanto o objeto quanto o agenciamento do acervo nocional anterior à sua incorporação - características do processo de ancoragem da novidade ao universo já conhecido:

Assim, o fato novo, arrastão, passou a significar algo a partir de sua percepção enquanto uma outra forma de um conflito já presente, interclasses e inter-racial. Ao mesmo tempo, ele é um signo novo, uma "novidade" tanto pela sua conformação quanto pelo espaço em que se deu - a praia, local pensando como imune a conflitos sérios. (Farias, 2003 p. 186)

\section{CONCLUSÃO}

Nas situações de crise, muitas vezes, para dar sentido ao que nos acomete, é preciso achar responsáveis. A mídia pode cumprir a missão de facilitar encontrálos, facilitar a ancoragem, refletindo sentimentos e imagens preexistentes na sociedade, sem problematizá-los. Condições contextuais concorrem para essas escolhas, como foi apontado. Assim, elaboram-se representações que renovam o repertório simbólico, por vezes preservando seu cerne. Para isso, selecionam-se aspectos do objeto que são recosturados em uma imagem de fácil apreensão por ecoar elementos do universo conceitual conhecido, no qual são acomodados são a objetivação e a ancoragem em ação - e responder a afetos circulantes na sociedade, trazendo à tona velhos fantasmas para lidar com novos sobressaltos, ou tirar partido deles. A base e o resultado desses processos neste caso foi, ao mesmo tempo, a produção de uma alteridade radical para um personagem que circulava em múltiplos territórios da cidade. A imagem pode chegar a uma naturalização, que torna o objeto algo tangível, quase material. $\bigcirc$ funqueiro se torna um perigo à vista, pela sua simples presença.

Não cabe, contudo, acreditar que tudo que foi dito pela mídia permanece, ou permanecerá. A desterritorialização e reterritorialização promovidas pelo funk, a briga de fronteira entre classes e grupos sociais prosseguem. Pode-se dizer que o funk vem operando nas duas últimas décadas "uma reposição simbólica da alteridade, recolocando o negro-pobre-favelado novamente em destaque, como o samba já fizera anteriormente..." (Laignier, 2008, p. 8). Com o funk, a favela tem-se inserido nos espaços de concepção-produção-difusão e recepção musical, nos espaços de fruição social e de debate cultural. As divisórias e bar- 
reiras se movem, desarrumando e rearrumando territórios, provocando uma multiterritorialidade. $\bigcirc$ funk burla sentinelas e atravessa as trincheiras da cidade. Pode-se dizer que "Nos últimos I 5 anos, o funk tem sido um elemento cultural carioca capaz de operar uma ressignificação dos lugares minoritários da 'cidade partida'"(Laignier, 2008, p. 13). O funqueiro, personagem deste redesenho que coloca a periferia no centro, é um transgressor, como foram no passado o sambista, o capoeira e outros mais. Sobre ele recaem temores e associações negativos, aos quais a mídia fez eco, como se viu. Esperemos que o tempo prossiga o seu caminho e que esta alteridade-síntese de outras da nossa história termine por se desconstruir ao ritmo contagiante do som que lhe deu vida.

\section{REFERÊNCIAS BIBLIOGRÁFICAS}

ABREU, M. A. Reconstruindo uma história esquecida: origem e expansão inicial das favelas do Rio de janeiro. Revista Espaço \& Debates, Rio de Janeiro, n 37, p.34-46, 1994.

ALVITO, M; ZALUAR, A. (Org.). Um século de favela. Rio de Janeiro: FGV, 2003.

ARRUDA, A. O Ambiente natural e seus habitantes no imaginário brasileiro. In:

(Org.). Representando a alteridade. Petrópolis: Vozes, 1998. p. 17-46.

Subjetividade, mudanças e representações sociais. In: FURTADO, O. GONZÁLEZ REY, F. L. (Org.). Por uma epistemologia da subjetividade: um debate entre a teoria sócio-histórica e a teoria das representações sociais. São Paulo: Casa do Psicólogo, 2002. p. 63-76.

BICALHO, P. P. G. Subjetividade e abordagem policial: por uma concepção de direitos humanos onde caibam mais humanos. 2005. Tese (Doutorado) - Instituto de Psicologia, Universidade Federal do Rio de Janeiro, Rio de Janeiro.

BRASILEIRO ELEGE I99I COMO O PIOR ANO. Jornal do Brasil, v. Cl, n. 264, p. I e 3, 29 dez. 1991. (material consultado em microficha da Biblioteca Nacional)

BULCÃO, I. A Produção de infâncias desiguais: uma viagem na gênese dos conceitos "criança" e "menor". In: NASCIMENTO, M. L. (Org). Pivetes: a produção de infâncias desiguais. Niterói: Intertexto, 2002. p.6I-73.

CANCLINI, N. Culturas híbridas. São Paulo: Edusp, 1998.

COIMBRA, C. M. B. Produzindo o mito da "guerra civil": naturalizando a violência. In: BATISTA, M; CRUZ, M. S; MATIAS, R. (Org.). Drogas e pós-modernidade. Rio de Janeiro: Eduerj, 2003. p. 165-174. 
DADOUN, R. A Violência. Rio de Janeiro: Difel, 1998.

DOUGLAS, M. Pureza e perigo: ensaio sobre as noções de poluição e tabu. Lisboa: Edições 70, 1991.

DOWDNEY, L. Crianças do tráfico: um estudo de caso de crianças em violência armada organizada no Rio de Janeiro. Rio de Janeiro: 7 Letras, 2003.

ENRIQUEZ, E. Da horda ao Estado: psicanálise do vínculo social. Rio de Janeiro: Zahar, 1983.

FARIAS, P. S. Pegando uma cor na praia: relações sociais e classificação de cor na cidade do Rio de Janeiro. Rio de Janeiro: Secretaria Municipal das Culturas, DGDI, 2003.

FERNANDES, F. L. Os Discursos sobre as favelas e os limites ao direito à cidade. Cidades, Presidente Prudente, v.2, n3, p. 37-62, jan./jun. 2005.

GINZBURG, C. Mitos, emblemas, sinais: morfologia e história. São Paulo: Companhia das Letras, 1989.

GOMES, A. C. et al. (Coord.). A República no Brasil. Rio de Janeiro: Nova Fronteira, 2002.

HAESBAERT, R. Dos múltiplos territórios à multiterritorialidade. Porto Alegre, set. 2004. Disponível em: <http://www6.ufrgs.br/petgea/Artigo/rh.pdf>. Acesso em: 13 jun. 2009. . Territórios alternativos. São Paulo: Contexto, 2002.

HERSCHMANN, M. O Funk e o hip-hop invadem a cena. 2.ed. Rio de Janeiro: UFRJ, 2005.

JODELET, D. A Alteridade como produto e processo psicossocial. In: ARRUDA, A. (Org.). Representando a alteridade. Petrópolis: Vozes, 2002. p.47-68.

. Os Processos psicossociais da exclusão. In: SAWAIA, B. As Artimanhas da exclusão: análise psicossocial e ética da desigualdade social. Petrópolis: Vozes, 1999. p.53-65.

. Representation sociale: phénomènes, concept et theorie. In: MOSCOVICI, S. Psychologie Sociale. Paris: Presses Universitaires de France, 1984. p. 357-389.

JOFFE, H. "Eu não", "o meu grupo não": representações sociais transculturais da Aids. In: JOVCHELOVITCH, S.; GUARESCHI, P. (Org.). Textos em representações sociais. Petrópolis: Vozes, 2003. p. 297-322.

JOVCHELOVITCH, S. Re(des)cobrindo o outro: para um entendimento da alteridade na teoria das representações sociais. In: ARRUDA, A (Org.). Representando a alteridade. Petrópolis: Vozes, 1998. p.69-81.

KRECH, D.; CRUTCHFIELD, R.; BALLACHEY, E. O Indivíduo na sociedade: um manual de psicologia social. São Paulo: Pioneira, 1975.

LAIGNIER, P. Contradições do funk carioca: entre a canção popular massiva e a sedução contra-hegemônica. In: CONGRESSO BRASILEIRO DE CIÊNCIAS DA COMUNICAÇÃO, 
31, Natal: Intercom, 2-6 set. 2008. Anais... Disponível em: <www.intercom.org.br/papers/ nacionais/2008/resumosR3- | 899- I.pdf> . Acesso em: jun.2009.

MAIOLINO, A. L. G. Espaço urbano e subjetividade: um foco especial sobre a favela do Canal das Tachas. 2005. Tese (Doutorado) - Programa de Pós-Graduação em Psicologia Social, Universidade Estadual do Rio de Janeiro, Rio de Janeiro.

MEDEIROS, J. Funk carioca: crime ou cultura? O som dá medo: e prazer. São Paulo: Terceiro Nome, 2006.

MENEGHELLO, R. Partidos e tendências de comportamento: o cenário político em 1994. In: DAGNINO, E. (Org.). Os Anos 90: política e sociedade no Brasil. São Paulo: Brasiliense, |994. p. $|5|-\mid 72$.

MOSCOVICl, S. Psychologie sociale. Paris: Presses Universitaires de France, 1984.

. Representações sociais: investigações em psicologia social. Petrópolis: Vozes, 2003.

PEREIRA, S. B. O Complexo de bode expiatório. São Paulo: Cultrix, 1990.

POBRES vão à praia (Os). Programa documento especial. Direção: Nelson Hoineff, Rede Manchete, 1989). Disponível em: <http://youtube.com/watch?v=FZry3YxPLOY>. Acesso em: 15 ago. 2008.

RAFFESTIN, C. Por uma geografia do poder. São Paulo: Ática, 1993.

RODRIGUES, E. Vem aí o verão do arrastão. Jornal do Brasil, Rio de Janeiro, p. I e 26, 3 nov. I 991. (material consultado em microficha na Biblioteca Nacional)

VALLADARES, L. Gênese da favela carioca: a produção anterior às ciências sociais. Revista Brasileira de Ciências Sociais, v. I5, n. 44, p.5-34, 2000.

VIANNA, H. Criminalização do funk. Revista Raiz, n. I, set. 2006. Disponível em: < http:// revistaraiz.uol.com.br/portal/index.php?option=com_content\&task=view\&id=98\&ltemid $=1 \mid 2>$. Acesso em: 15 ago. 2008.

. O Funk como símbolo da violência. In: VELHO, G.; ALVITO, M. (Org.). Cidadania e violência. Rio de Janeiro: UFRJ, 1996. p. I78-187.

. O Mundo funk carioca. Rio de Janeiro: Jorge Zahar, 1988.

ZALUAR, A. Condomínio do diabo. Rio de Janeiro: Revan, UFRJ, 1994.

Recebido em: julho 2009

Aprovado para publicação em: março 2010 